\title{
Breast Carcinoid Tumor
}

National Cancer Institute

\section{Source}

National Cancer Institute. Breast Carcinoid Tumor. NCI Thesaurus. Code C5170.

A carcinoid tumor that arises from the breast. Primary carcinoid tumors of the breast are rare; most cases represent metastases from other anatomic sites. 